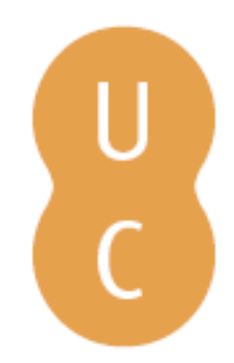

\title{
nommalina
}

\section{Hermenêutica da educação: um desafio aos cánones epistemológicos das Ciências da Educação}
Autor(es):
Carvalho, Adalberto Dias de
Publicado por: Imprensa da Universidade de Coimbra
URL
persistente:
URI:http://hdl.handle.net/10316.2/38389
DOI:
DOI:http://dx.doi.org/10.14195/978-989-26-0486-2_11
Accessed : $\quad$ 26-Apr-2023 15:07:55

A navegação consulta e descarregamento dos títulos inseridos nas Bibliotecas Digitais UC Digitalis, UC Pombalina e UC Impactum, pressupõem a aceitação plena e sem reservas dos Termos e Condições de Uso destas Bibliotecas Digitais, disponíveis em https://digitalis.uc.pt/pt-pt/termos.

Conforme exposto nos referidos Termos e Condições de Uso, o descarregamento de títulos de acesso restrito requer uma licença válida de autorização devendo o utilizador aceder ao(s) documento(s) a partir de um endereço de IP da instituição detentora da supramencionada licença.

Ao utilizador é apenas permitido o descarregamento para uso pessoal, pelo que o emprego do(s) título(s) descarregado(s) para outro fim, designadamente comercial, carece de autorização do respetivo autor ou editor da obra.

Na medida em que todas as obras da UC Digitalis se encontram protegidas pelo Código do Direito de Autor e Direitos Conexos e demais legislação aplicável, toda a cópia, parcial ou total, deste documento, nos casos em que é legalmente admitida, deverá conter ou fazer-se acompanhar por este aviso.

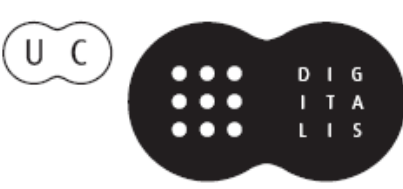


João Boavida

Ángel García del Dujo

Coordenação

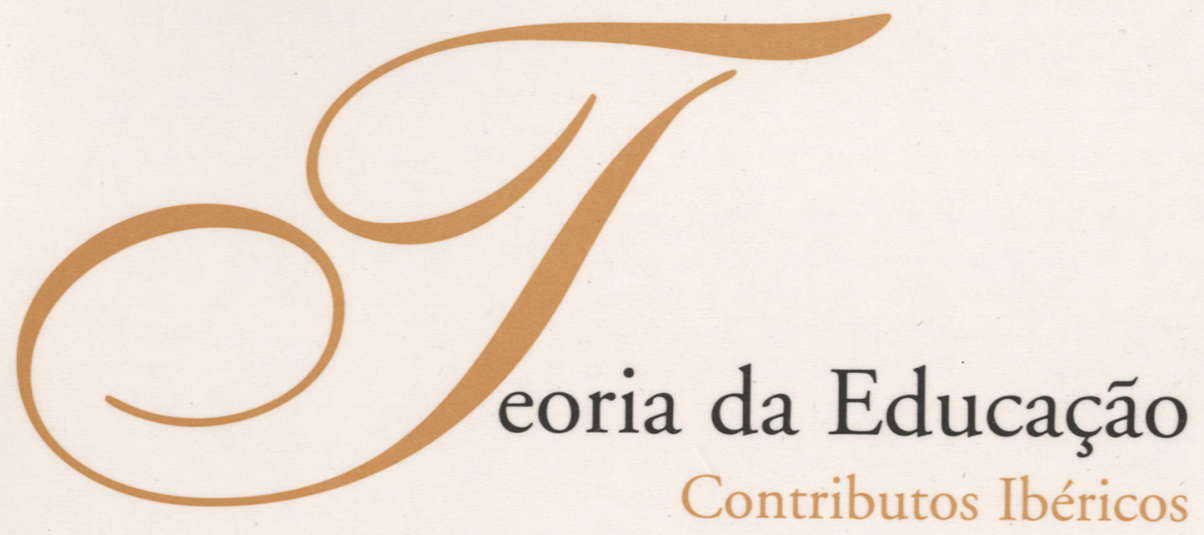


A dal berto Dias de Carvalho

Universidade do Porto

Her menêutica da Educação:

UM DESAFIO AOS CÁNONESEPISTEM OLÓGICOSDAS CIÊNCIAS DA EDUCAÇÃO

\section{0 círculo epistemológico inaugural das ciências da educação}

Vivemos urna época de facto problemática no domínio da educação. Na verdade, se esta desfruta hoje de um reconhecimento generalizado que lhe confere um estatuto social privilegiado, por outro, esta projecção é acompanhada de urna clara fragilização da sua autonomia e, talvez até, da sua identidade. Este fenómeno, tanto mais evidente quanto a educação é identificada como um dos elos do desenvolvimento humano, é constatável com a afirmação generalizada do seu carácter eminentemente económico e político. Claro que 0 sendo, porém, desde 0 momento em que de urna simples constatação se passa a uma estratégia de apropriação e a um projecto de exercício hegemónico, então, as questões do poder passam à primeira linha e, com elas, pensamos, a educação perde uma parte significativa da sua identidade que precisamente a investigação educacional de cariz científico tinha alegadamente procurado conferir-lhe, subtraindo-a ao domínio tradicional da religião e da pedagogia. Uma identidade que, aparentemente atribuindo um poder próprio à educação pelo reconhecimento do homo educandus enquanto sujeito ético, estético, social, económico e político, inviabilizava, em princípio, a sua submissão -e tendencialmente a sua dissolução $\longrightarrow$ sob qualquer uma destas perspectivas, 0 que acaba por ocorrer realmente desde que estas incidam do exterior sobre ele. 
A cientifização da educação emprestou-he, pois, num primeiro momento, a possibilidade de esta escapar a uma regulação segundo estritos propósitos doutrinários religiosos e também políticos, já emergentes designadamente a partir da instauração da matriz revolucionária iluminista. Procurou igualmente evitar 0 seu enovelamento em utopias pedagógicas especulativas que aparentemente lhe retiravam também 0 controlo sobre 0 seu próprio espaço de teorização e intervenção.

As ciências cia educação ou a investigação educacional —expressões dominantes, respectivamente nas áreas de influência francófona e anglófona — encontraram assim um promissor e fecundo terreno para a sua implantação, crescimento e reconhecimento. Para o efeito, como se sabe, começaram por adoptar metodologias reconhecidas pelo paradigma de cientificidade dominante $\longrightarrow$ positivista — para depois adaptaram metodologias reinantes entre as ciências sociais e humanas, elas mesmas entretanto em busca da sua própria especificidade — referimo-nos às chamadas metodologias qualitativas e aí sobretudo às metodologias participantes.

Em todas as circunstâncias, a preocupação dominante, historicamente explicável, era a de se respeitar as exigências de ordem metodológica como forma de se assegurar 0 reconhecimento no seio da comunidade científica e, a partir daí garantir a dignidade e 0 prestígio académico e social.

\section{Os desafios da superação do panlogicismo epistemológico}

Acontece que, ao fazer-se agora um balanço de quarenta anos de ciências da educação no panorama internacional e de aproximadamente trinta entre nós, se é constatável a existência de uma produção assinalável de artigos e livros, a par da configuração de uma comunidade de investigadores que organiza sistematicamente eventos e promove formações na área, verdade é também que facilmente se surpreendem enormes fragilidades, impasses e desajustamentos. 
Assim:

- As comunidades de educadores continuam frequentemente a sentirle defraudadas nas suas expectativas quanto aos resultados e à ${ }_{297}$ funcionalidade dos estudos empreendidos.

- Os políticos e os economistas, escudados no bom-senso, proclamam bem alto a prioridade das suas avaliações e propostas, em nome do progresso e do bem-estar das populações e, bastantes vezes, explícitamente contra os cultores das ciências da educação.

- As chamadas ciências contributivas, designadamente a sociologia e a psicologia, continuam a afirmar-se como protagonistas da investigação pertinente no campo educativo, utilizando nesse sentido a mais-valia que representa a sua maior longevidade e inerente credibilidade social, ainda que à custa de uma desfocalização da identidade educativa das problemáticas tratadas em proveito das ópticas disciplinares de partida.

- As ciências da educação hesitam, entretanto, entre, por um lado, um quantitativismo duro que, embora sendo um exercício de rigor, lhes retira concreticidade, e, por outro, um militantismo que, aspirando a escapar ao abstraccionismo, cai, com demasiada frequência, na banalidade pretensamente ratificadora de slogans, enquanto tais desprovidos de validade fora da equivocidade que os sustenta e quase os universaliza.

- As ciências da educação acabam curiosamente por ficar prisioneiras do cientismo que as vincula indelevelmente à omnipotência dos critérios metodológicos ou do pedagogismo que as mantém a reboque dos truismos e dos lugares comuns, seja de rotinas imobilizantes, seja de revoluções diletantes que, quantas vezes, as lançaram no pântano da alienação política. Ora, é neste contexto crítico que ganha força, dentro da própria educação, um saber renovado: 0 saber pedagógico. A chamada prática reflectida é disso um bom exemplo. 
0 saber pedagógico é então, sobretudo, 0 resultado de uma prática projectiva de mediação, refractária a uma obsessiva objectivação na exacta medida em que esta última visa a redução da realidade dos processos educativos à dimensão de um objecto da actividade de investigação com a consequente ocultação dos sujeitos dentro dos limites das suas próprias sombras que são justamente 0 Método e 0 Objecto no quadro de urna soberania racionalista.

Contudo, a superação deste último panlogicismo passa por um diálogo com uma prática — os respectivos actores —que, apesar de tudo, quanto mais não seja pelo carácter refractário das rotinas do seu quotidiano, permanece exterior a uma sistematização racional cujo braço político é representado pelos sistemas educativos. Será por isso vital despertar urna dinámica de construção dos saberes, das práticas e dos actores que, estranha às lógicas de coerência epistemológica, se abra às vicissitudes do vivido sem por ele ficar enredada e, muito pelo contrário, antes nele captando e, mais do que isso, vivendo, pleonasticamente, a sua complexidade.

Deste modo, importará evitar:

- A imposição, segundo critérios privilegiadamente epistemológicos, de objectos e de métodos a todos os campos do saber.

- A definição apriorística de fronteiras entre saberes teóricos e saberes práticos.

- A afirmação hegemónica do poder de urna lógica de produção de conhecimentos e de coerência de saberes.

- 0 esquecimento da dialéctica entre disponibilidades e projectos, ou seja, das relações entre possibilidades (objectivas) e oportunidades (subjectivas). 


\section{Saberes da prática e processos de intersubjectivação}

A partir da problemática das relações entre os saberes da prática e os da investigação educacional teórica confrontamo-nos quer com as interpelações recíprocas levantadas pelas suas intersecções institucionais, quer com a questão das correspondências —e das incomensurabilidades —entre as lógicas de cada um destes dois saberes diante das necessidades efectivas das situações educativas, dos seus protagonistas e dos seus destinatários. A um tal propósito, importa ainda acrescentar as intervenções das perspectivas corporativas que alimentam reivindicações sectárias a propósito da responsabilidade recíproca acerca dos êxitos e dos fracassos desencadeados pelo desenvolvimento dos processos objectivos.

De toda a maneira, constata-se, em princípio, uma cumplicidade objectiva, frequentemente distorcida, entre estes dois grupos na medida em que cada um espera finalmente do outro a ratificação das suas propostas: os práticos esperam 0 reconhecimento da dignidade dos seus saberes; os teóricos pretendem a aceitação da validade empírica das suas conclusões. Só que, em educação, exige-se fecundidade aos enunciados e não apenas uma receptividade passiva do real constatado. É justamente aqui que esses enunciados tendem a separar-se definitivamente, por exemplo, dos estudos sociológicos que, mais do que contribuírem para a transformação do mundo, 0 espelham na sua estrutura nuclear e 0 ratificam na frieza das estatísticas e das respectivas análises. Mas é também aqui que os enunciados educacionais, enquanto transgredidos por propósitos educativos, se encontram perante uma intricada e complicada aproximação aos registos retóricos, opinativos e doutrinários. Tanto mais que a investigação educacional científica se depara, desde 0 início, com um corpo de saber já constituído pela tradição e com poderes nele e por ele instituídos.

Assim, mais do que nunca, como o constatou M. Bernard (1989) —um pouco sobre M. Weber - a racionalidade lógica é sempre, de uma certa maneira, uma reelaboração e, assim, uma reformulação da racionalidade 
axiológica em que os fundamentos se misturam com os princípios e em que se delineiam jogos de valores implícitos e explícitos: é nestas condições que os práticos alimentam a expectativa, como se disse, de que os teóricos organizem discursos que justifiquem as suas práticas e as suas intuições enquanto que estes exploram as práticas como campos de aplicação e de confirmação das suas construções, ou seja, enquanto espaços de legitimação de saberes. Instauram-se assim círculos de reiteração, os quais são rompidos precisamente quando emergem segmentos de não coincidência entre as lógicas em causa.

Em nossa opinião, as pesquisas qualitativas surgem aqui como uma área simultaneamente privilegiada e crítica de convergências e divergências na medida em que, enquanto epistemológicamente reconhecidas como válidas, permitem, por recurso a uma metodologia científica que surge como aberta, 0 enquadramento da empatia, da interacção, do urgentismo e do intuicionismo dos actores educativos até ao exacto ponto em que os procedimentos utilizados e as conclusões alcançadas por estes começam a desestabilizar os limites da canónica cientista. Então, a tolerância termina e assiste-se à eclosão de dissidências marcadas por actos de não reconhecimento institucional ou pela captura de noções empíricas ou experienciais por parte de operações de conceptualização conduzidas, a qualquer preço, até à sua consumação.

Eis 0 que se passa, por exemplo, no domínio dos valores a partir do momento em que se passa das morais características das acções educativas do terreno para as construções próprias das éticas científicas: rapidamente se substituem os princípios das convicções da intersubjectividade pela correcta fundamentação das axiomáticas trans-subjectivas. Os conceitos são nessa altura colocados nos lugares, entretanto esvaziados, das representações subjectivas com uma consequente valorização das preocupações com a verificação e com a universalidade abstracta e uma implícita lateralização das interacções interpessoais.

Descobrem-se assim as fronteiras que envolvem, percorrem e condicionam 0 debate e que sustentam a própria estabilidade relativa das identidades 
— existentes, impostas ou desejadas — das práticas, dos actores e das investigações.

Constata-se, deste modo, que, permanecendo-se no ámbito do referido quadro epistemológico e, mais ainda, no quadro da epistemología enquanto tal, não poderemos nunca colocar-nos numa posição de exterioridade relativamente ao campo das significações de referência, isto é, numa perspectiva de eventual superação efectiva de paradigmas, tendo-se de aceitar a inevitabilidade de nos deixarmos anular no interior do círculo vicioso dos jogos de justificação e de legitimação já identificados. Jogos que, de acordo com Boutinet (1990), ligam as ortodoxias às ortopraxias. É por estas razões que propomos como alternativa de principio o delineamento de parâmetros hermenêuticos para as posições em confronto que, sendo limites de sentido, serão sempre também passagens abertas para 0 debate e para as possibilidades da sua superação a partir de constatações e de pontos de vista diferenciados.

A dinâmica dos processos interactivos e complementares de objectivação e de intersubjectivação ocupará então o lugar da aplicação passiva dos critérios de ordem metodológica impostos nos espaços aparentemente vazios deixados pelas antropologias do conceito e da ausência (do sujeito).

\section{O lugar incontornável da crítica hermenêutica}

Esta atenção reforçada aos limites justifica-se por uma tripla razão: por um lado, porque de facto os actores da cena educativa — para além das intervenções conjunturais dos professores —raramente entram na denominada cozinha dos debates especializados sobre problemáticas educativas, deixando este domínio aos guardiões do poder epistemológico; por outro lado, porque, como consequência destas restrições, as interrogações e as interpelações conservam-se sempre no quadro restrito —e deslocado —das 
correspondências ou das distâncias entre a investigação teórica e a prática; por outro lado ainda, porque se continua, de uma maneira clara ou subtil, a subtrair o campo imenso (e, por isso, difícil de controlar) dos media e do marketing ao terreno do debate educativo que, por acréscimo, se insiste em restringir aos limites do círculo do debate educativo escolar.

Esta situação provoca, do lado dos actores educativos, o desenvolvimento frequente de atitudes quer de submissão, quer de demissão, quer de militância reactiva, enquanto que os investigadores canónicos proclamam, em última instância, o reconhecimento de um espaço epistemológico para 0 saber pedagógico entendido este como um saber específico dos práticos - tolerado e, de um modo ou de outro, assim capturado. Mas, finalmente, as ciências da educação não evitam verem-se confrontadas cada vez mais com as críticas que as acusam de ausência de eficácia e de um afastamento progressivo da realidade. Estas acusações são também frequentemente acompanhadas, como vimos já, por uma consciência aguda do papel dominante desempenhado, a partir do exterior, por ciências contributivas mais tradicionais como a psicologia e igualmente por outras mais jovens como as ciências da comunicação; em simultâneo, ao nível interno, sente -se cada vez mais a impotência proveniente do bloqueamento axiológico imposto pela ortodoxia positivista que, precisamente sob 0 pretexto de uma crítica à normatividade pedagógica, se traduz pela criaçãa de um hiato antropológico que se torna incompatível com a educação olhada como uma antropologia prática.

Por outro lado, a adopção, entre nós casuística, de metodologias participantes, de práticas reflexivas ou de investigações heurísticas por alguns sectores mais activos de educadores, se representa um esforço notável de afirmação de uma nova identidade, enfrenta também a difícil conciliação da dinâmica normativa e reguladora da educação, entendida sobretudo como uma prática social, com uma intencionalidade da investigação, esta última encarada como uma prática de problematização que será, a partir daí, subsidiária da linha nómada de que nos fala G. Deleuze. 
Em nossa opinião, partindo-se dos contributos críticos designadamente de Ricoeur (1990) e de Gadamer (1996), importará recomeçar todo o debate acerca das relações entre as ciências da educação e 0 saber pedagógico, aceitando-se, para este efeito, 0 reconhecimento de uma ruptura prévia com a autocracia da vigilância epistemológica e, concomitantemente, a validade da afirmação do valor da crítica hermenêutica.

Esta inversão obrigará à distinção entre sentido e verdade, o que significa, segundo Ricoeur (1990), que cada um de nós deverá ser capaz de reconhecer sentidos às posições adversas, apesar do facto de a verdade supor uma convicção que igualmente se reconhece. Daí 0 lugar decisivo da aceitação da educação fundamentalmente enquanto uma prática antropológica e não mais como uma simples actividade de produção de bens materiais e humanos (como passará a ser 0 caso desde que ela seja perspectivada apenas e somente segundo os pontos de vista sociológico, económico e cultural), ou de saberes — científicos — como terá tendência a passar-se desde que impere um olhar estritamente epistemológico.

Demarcamo-nos assim do objectivismo sem cairmos no perspectivismo, do dogmatismo sem abrirmos as portas ao niilismo. A intersubjectivação e a contextualização — duas dimensões centrais da educação —encontram, entretanto, as duas em conjunto, os seus direitos de cidade e, com elas, a conciliação dialéctica entre sentidos (mais subjectivos) e significados (mais objectivos), 0 que representa um ganho em termos da viabilização conjunta dos processos de personalização (idiossincráticos) versus processos de universalização (objectivantes). Esta nova postura passará a valorizar, deste modo, mais as relações dos diferentes sujeitos com a verdade —reconhecidos aqueles assim como actores da saber e, por esta via, da cena educativa - do que as relações das várias disciplinas com essa mesma verdade, 0 que representa, por acréscimo, uma concepção radicalmente nova da própria pluralidade. 0 saber é agora 0 saber próprio e 0 saber dos outros, todos reconhecidos como sujeitos que, consumindo e elaborando saberes, se constituem antropológicamente, construindo os seus próprios lugares 
na sociedade. Esta é a itineráncia antropológica que justifica a educação e que esta, por seu turno, alimenta.

Eis, em síntese, 0 importante desafio que 0 processo de edificação do saber pedagógico coloca, para além da estrita coerência do seu perímetro epistemológico delineado nos bastidores da investigação educacional: de facto, agora, não se trata mais de alargar apenas 0 manto da ciência aos corredores da reflexão pedagógica ou de aperfeiçoar a cientifização da investigação educacional, mas, muito mais do que isso, partindo-se dos seus impasses, das suas interpelações e das suas interrogações, trata-se de pôr em causa os próprios fundamentos sobre os quais foi erguido, durante as últimas décadas, 0 edificio das ciências da educação. Tudo isto, alterándose também, para além dos pressupostos, os propósitos: a preocupação central não é já a de consolidar a lógica científica por si mesma, propósito que a epistemología servia, mas a de garantir e consolidar, inclusive com as abordagens científicas, 0 perfil antropológicamente consequente da educação para a dignidade dos seus actores e, em todas as circunstancias, para a afirmação ética dos seus destinatários perante as práticas e os saberes, concebidos ambos como cimento e estrutura da sua humanidade, nomeadamente em situações delicadas de relação com 0 poder e de fragilidade inquietante dos limites.

Trata-se, finalmente, de um verdadeiro efeito boomerang em que 0 impacto do retorno (hermenêutico) não repete —e, mais ainda, interroga — 0 do lançamento (epistemológico) que 0 desencadeou, provocando urna efectiva ruptura de paradigmas não tanto de saberes mas, sobretudo, de atitudes perante e com os saberes. 


\section{Bbl iografia}

Bernard, M. (1989). Critique des fondements de l'éducation, Paris.- Chiron.

Boutinet, J.-P. (1990). Anthropologie du projet, Paris: PUF.

Carvalho, A. D. (2002). «Où sont, où vont les savoirs en éducation?», in J. Donnay;

M. Bru, (Eds.): Recherches, pratiques et savoirs en éducation, Bruxelles: de Boeck.

Gadamer, H.-G. (1996). La philosophie herméneutique, Paris: PUF.

Ricoeur, P. (1990). Soi-même comme un autre, Paris: Seuil. 